\title{
RE-CONTEXTUALIZING SHAKESPEARE: ROMEO AND JULIET IN MANGA
}

\author{
ANDREEA ŞERBAN \\ West University of Timişoara
}

\begin{abstract}
A fairly new medium for westerners, manga joins the variety of already existing "shakespeares", bringing a fresh and vivid perspective on some of the most famous Shakespearean plays. This paper discusses several representations of space, with a particular focus on the city (Verona), the Capulet ballroom, and Juliet's bedroom, as they are rendered by artists in three manga transmediations of Romeo and Juliet coming from different cultural contexts (British, American, and Japanese). The paper will also explore the ways in which the three cultures play with Shakespeare's original Italian setting and negotiate their influence over one another at the beginning of the twenty-first century.
\end{abstract}

Keywords: manga, Romeo and Juliet, Shakespeare, space, transmediation

\section{The Romeo and Juliet Space}

It is a well-known fact that space and spatial representations are essential in any theatrical performance. In a recent publication dedicated to Shakespeare and space, Habermann and Witten (Habermann and Witten 3) identify seven types of space in Shakespearean drama: "(1) structural/topological space, (2) stage space/setting/locality, (3) linguistic/poetic space, (4) social/gendered space, (5) early modern geographies, (6) cultural spaces/contact zones, and (7) the material world/cultural imaginary." In the editors' approach, the first type of space concerns the "structural patterns in the plays themselves and the way in which these patterns are transferred onto the stage" (Habermann and Witen 4); the second type deals with the actual performance; the third type refers to how the text is organized on the page as well as to how the blank verse allows characters to freely manifest their personality; the fourth type of space is centred on social interaction, practices and relations of power; the fifth type focuses on Shakespeare's geographic imagination and his understanding of exotic places; 
the sixth type of space relies on the impact Shakespeare had on other cultures, influencing other cultures' literary productions; finally, the last type of space is concerned with how the literary text affects our perception of the material world (for example, the ways in which the play Romeo and Juliet shape our perception of the city of Verona, particularly "la casa di Giulietta" with its added balcony meant to re-enact the lovers' second meeting, yet a detail which does not even exist in the original play (Şerban 67-70). Of these seven aspects of the spatial paradigm, special attention will be paid to the linguistic space, the social space, and the cultural space, all of which are exploited in the manga transmediations of Romeo and Juliet that will be discussed in the following sections.

Furthermore, to show the versatility and to suggest the plethora of adaptations the star-crossed lovers' story has inspired in time, Reynolds and Segal (38) coined the term "R\&J space", which is meant to designate "a conglomeration of the official and/or unofficial historical, political, cultural, and social spaces through which Romeo and Juliet resound in various manifestations, ranging from emblems of romantic love, legitimaters of forbidden desire, icons of teenage angst, and, in more recent critical incarnations, subversive agents of dominant ideologies substantiated by the names they themselves are so eager to doff." Elsewhere, the scholars further explain "R\&J space" as representing a diversity of "social, cultural, political, and historical spaces generated, inhabited, and affected by Romeo and Juliet." (Reynolds and Segal 41)

It is at the crossroads of such diverse spaces that manga also lies. A fairly new genre for westerners, manga relies on oriental drawing styles and cinematographic narrative techniques to present new and even classical literary works especially to a young visually prone audience, thus contributing to the constant creation of new versions of Shakespeare "in an age of global mobility" (Greenblatt 2), re-positioning his work at the crossroads of two highly different cultural zones: the east and the west.

This paper will therefore discuss three different manga adaptations of Romeo and Juliet, one of the most successful Shakespearean plays among adolescents today and usually marketed as an example of teenage love (Wetmore 381), aiming to explore how the spatial paradigm is exploited in such a medium, while also looking at the way in which each transmediation refreshes and adds layers of meaning to the familiar plot. Thus, in chronological order, the first manga version I will consider appeared in Britain in 2007, as part of the fourteen-volume Manga Shakespeare collection published by SelfMadeHero Publishing House. The plot was abridged to fit the collection format and standard (about 200 pages) by Richard Appignanesi, a linguistically resourceful editor and Shakespeare scholar, while the illustrations were provided by artist Sonia Leong. What differentiates it from the other two versions is the "dramatis personae" section, which shows colourful representations of the characters, accompanied by a representative line from the plot. For instance, both Romeo 
and Juliet are presented in separate frames on the same page. Romeo is a blond rock star, wearing a tight turtle-neck and a leather jacket, and singing with a passionate sadness into a microphone "Did my heart love till now?" On the other hand, a fashionable pink-dressed Juliet with dark eyes and hair is half sitting half lounging, a look of longing on her face, while she is listening to Romeo singing on TV behind her; her line reads "My true love passion..." The British manga, which moves the plot to modern-day Japan, adds meaning to the Shakesperean play from the very introduction: Juliet is familiar with Romeo's face and voice since she listens to his music, yet strangely, she does not (or pretends not to) recognize him at the ball.

Second comes an American version from 2008, belonging to the sevenvolume Manga Edition collection, edited by Adam Sexton and drawn by Yali Lin. The plot is again abridged to fit the format, while each act is introduced by a one-page frame of the most important moment in it alongside with a representative line. For example, the first act is represented by a medium-sized frame showing Romeo's face in close-up, just as he realizes Juliet is his father's enemy's daughter. The fact that he is drawn as if leaning towards the viewer's right, as if out of balance, together with his befuddled expression (mouth agape, eyes wide open and eyebrows raised), create a powerful representation of shock. The speech bubble accompanying the frame reads: "Is she...a Capulet? O dear account! My life is my foe's debt." (Sexton and Lin 5)

The third and final version to be discussed is a Japanese spin-off adaptation by artist COM, which was released in 2010, following the success of an anime (animated film) version entitled Romeo X Juliet. This plot strays from the original in terms of details, with Juliet eventually turning into the tree Escalus that will forever support the floating island of Neo Verona, but the main stages of the lovers' relationship are retained: they meet, fall in love, marry, separate, and eventually die. The ultimate message this manga conveys is that, the lovers' death actually reunites them in the afterlife, or they earn the right to an eternal ever after "Because they saved us all..." (COM 368). In terms of structure, the Japanese manga version also includes a few colourful pages introducing the most important characters, while each of the eight acts in which the story is structured shows the characters that are most important for that part of the plot. The only colourful such page is the one dedicated to act one, which shows a blue-attired Romeo and a red-dressed Juliet meeting in a field of white irises, surrounding some ruins. There is opposition as well as complementarity between the colours associated with the warring houses-red for Juliet Fiammata Arst De Capulet, her passion and courage but also sacrifice and early loss of her family; and blue for Romeo Candore De Montague, his wisdom, honesty, loyalty and selflessness (as their middle Italian names also suggest).

Briefly put, what all these manga adaptations have in common is a combination of visual language and text per se. In addition to this, mangas also 
use black and white drawings, irregular frames, large-eyed characters, elongated limbs, and effeminate young male characters typical of the "shojo manga" addressed to girls (cf. Şerban 22-23). Last but not least, Shakespeare's original language (the American versions), an illusion of it (the British version), i.e. "smart equivalents for old structures that truly illuminate the play today" (Jensen 400 ), or modern language (the Japanese version).

\section{The Linguistic Space}

As regards the "linguistic space" (Habermann and Witen 5) or the arrangement of the text on the page, the British version uses Shakespeare's original language in an abridged form, while the speech bubbles corresponding to each character are mostly irregular in shape, sometimes even without any outline whatsoever. Comparatively, the American version employs Shakespeare's original language, occasionally shortened, but usually inserted in round or oval speech bubbles sometimes replaced by irregular or cloud-shaped balloons. Finally, the Japanese version uses modern English sprinkled now and then with archaic words inserted in predominantly irregular speech balloons.

The biggest difference concerns the reader's space, i.e. the way in which the mangas are read. Although in all three the text is read from the top of the page towards the bottom, the British and American versions are read the western way, from left to right, whereas in the Japanese version the reader/viewer should move from the right to the left of the page, as is traditional for this culture and genre, but which requires the western reader to get out if his/her comfort zone and develop a new reading skill.

In what follows, I will discuss three types of spaces: one public or social (the city), one private made public (the Capulet ballroom), and one private (Juliet's bedroom), with the main purpose of exploring how these three locations are conveyed at the crossroads of western and oriental cultures, and what additional meanings are brought into the reading of the original Shakespearean play.

\section{The City}

In itself, the city is given only minor attention. It represents a public space of masculine authority (embodied in the Prince), a social space governed by laws, political interests and etiquette. The original play of Romeo and Juliet highlights two important things related to the city of Verona. Firstly, the city has a commerce-based official culture, illustrated by the many money metaphors, and talks of money, interest and value (Reynolds and Segal 46-49), all of which are meant to suggest the wealth of the feuding Capulets and Montagues. Reynolds 
and Segal (45) provide a compelling insight into the family feud within the context of the political system of Verona, which is structured by "mercantile exchange" and dominated by the "language of commerce" (49). In these scholars' perspective, the family feud (represented by repeated practices not just between family members but also between their servants), actually accounts for the "feuding ideologies" of the two families' heads. For instance, while we do not know very much about the Montagues except that they are rich and influential, we do find out that Lord Capulet's wealth and influence are changeable in the city, depending on the speaker's perspective: while the Capulet servant Peter refers to his master as "the great rich Capulet" (1.2.80-81), Juliet's father himself talks to Paris about his "poor house" (1.2.24; cf. Reynolds and Segal 47), thus suggesting his greedy nature and mercantile approach to all aspects of life, including his daughter's marriage.

Secondly, there is an illusory atmosphere of peace since the feud-most likely based on financial rivalry-between the two families seems to be the dominant ideology in Verona, with the very first scene showcasing the practice of the two houses' servants using verbal aggression and physical violence against one another, as an extension of their masters' quarrel. However, in the three mangas under discussion, the city represents a cultural contact zone, overlapping Shakespeare's original choice of location with the new settings chosen by these modern transmediations.

The British version is the most modern re-contextualization of the three, having moved the plot in modern-day Tokyo, a real, topological space, depicted however in only one frame, at the very beginning. The linear perspective is meant to attract the viewer into the story. Occupying an entire page, the frame shows a busy shopping street, with banners hanging from the lampposts. Subsequent smaller frames depict the feud between the two families' servants as a conflict between Yakuza gangs, using samurai swords. The underlying suggestion is that both the Capulets and the Montagues are equally important and influential in the city, even though the Capulets are shown as greedier and more vulgar. The twenty-first century city is further completed by the characters' fancy fashionable outfits. For example, the introductory pages replacing the traditional "dramatis personae" section shows Juliet in a pink kimono-inspired tunic with a wide green and yellow girdle, shorts in a matching darker colour fitted with long dark stockings, while Romeo wears modern clothing comprising kaki trousers, a dark and very tight turtleneck, a brown leather jacket and dark boots. It is also worth mentioning that each family has a parent wearing a modern outfit (Lady Montague, Lord Capulet), whereas the other has traditional oriental clothing (Lady Capulet, Lord Montague) — which points to a mixture of tradition and modernity, a symbolic negotiation of Shakespeare's plot with its twenty-first century relocation. 
The American manga is the most faithful to Shakespeare's original, keeping the setting in Renaissance Verona, another real, topological space. This manga begins with the city being depicted in two large frames-one aerial and panoramic, the other linear - both of which create in the reader a feeling of detachment and objectivity. The focus is here on the marketplace, where people shop for groceries and where the servants of the feuding families meet. The surrounding buildings are made of stone and are also emblematic of Italian Renaissance architecture. The overall suggestion is that the conflict is based on haggling, thus emphasizing the official commercial culture of Shakespeare's imagined Verona. Moreover, this manga retains the original Renaissance atmosphere of the city, extending it to the characters' outfits. For instance, Romeo wears tights, a matching tunic worn over a white undershirt and laced with black ribbons on the sides and on his sleeves. Juliet too wears a long highwaisted dress, her sleeves tied with ribbons to her wrists, elbows and shoulders. Socially speaking, just as in the British version, the viewer/reader understands that the Montagues and the Capulets are equally important families in the city.

By contrast, the Japanese version moves the setting to an alternative universe, where the city of Neo Verona has developed on a floating island. The two small frames, which show a linear depiction of the city, involving the viewer in the story, are shown only on the second page of the plot, after the introduction of a conflict between some soldiers and the Red Whirlwind, a vigilante who stops just in time to witness the unjust execution of a poor citizen. The initial general atmosphere suggested is one of tyranny and violence, and readers/viewers can infer that the conflict will be centred on the age-old conflict between good and evil. The dominant ideology is far from objective here and since the Prince is actually Montague himself, there is no death-promising condemnation from a higher authority to stop the smouldering feud. As the story progresses, readers find out that the Capulets - of whom Juliet is the only survivor, masquerading as the Red Whirlwind - are (or rather used to be) good and just people, protecting the citizens irrespective of their social status. On the other hand, Lord Montague in particular-shown in this spin-off manga as the usurper of the rightful ruling family - is shown as evil, cruel and oppressive of the commoners. As concerns the city of Neo Verona proper, it looks medieval, with buildings made of big rocks, creating an illusion of time accuracy in relation to Shakespeare's original play, a fairy-tale-like setting. Overall, the city of Neo Verona is the most heterotopic space, an alternative to Shakespeare's entire dramatic world, not just in terms of setting but also in terms of characters borrowed from many other plays (e.g. Cordelia, Ophelia), including Shakespeare himself as a theatre director.

Before moving to the next space type, it is important to mention that, whereas in the British and the American versions, the Capulets and the Montagues have different homes, in the Japanese spin-off, the usurping 
Montagues live in the former Capulet palace, having taken over all their possessions and privileges. Here, it is only one home that stands for the marker of high social status and supreme social and political authority.

\section{The Capulet Home}

The ballroom is in fact a liminal place, a private space turned public for the occasion of the ball. Designed to entertain guests, the ballroom is a place of transition from the open public space of the city to the privacy of domestic life.

The most striking feature common to the Capulet ballroom in all three mangas is its western aristocratic look. In addition to hosting one of the most romantic courtships in cultural memory, the frames dedicated to the ball scene are also meant to show off the Capulets' fortune and high social status, relying on cultural practices and power relations. As mentioned earlier, Lord Capulet has a fluctuating value in the commercial city of Verona: although considered rich by his servants, his wealth cannot be compared to that of Paris, whom he wants to secure as a son-in-law/ financial ally. Furthermore, the ballroom is also the space where Romeo and Juliet first meet, showing Juliet as confined not only by her father's authoritarian behaviour but also by the walls of his house.

The British manga shows an aristocratic interior with columns and two twin stairs with an interior balcony from which Lord Capulet looks down at his guests. In terms of furnishings and decoration, only tables with some food are visible. There is one electric chandelier, which seems rather minimalist than impressive. The overall impression is of a rather stiff party, where guests seem to just pay their social dues and not actually enjoying themselves. Nonetheless, the background abounds in stars and bubbles, anticipating the appropriate circumstances for young love. Romeo starts his courtship of Juliet next to a column and a table with a swan ice-sculpture. The implied association is that Juliet is as cold as ice, in need of warm words (Romeo's pun on hands, pilgrims and kiss) and gestures (the actual kiss) to "melt" her heart.

The American version renders the ballroom as made up of two parts between which some steps make the transition, a symbolic interpretation of Lord Capulet's changeable value on the Veronese market and his wish to constantly improve his status and expand his influence. The American manga ballroom seems very romantic, with wooden torches on the walls and tables with large platters of food and fruits. Here, Romeo's courting of Juliet takes place near a food-laden table, which turns Juliet into edible commodity, different from the mercantile interpretation of the lovers' courting and relationship postulated by Reynolds and Segal (49-57).

The Japanese manga features by far the most impressive and ostentatious interior, a grand palace-like ballroom, with a royal staircase and 
balcony from which Lord Capulet addresses his guests. Decorations abound: rich pillars and columns, paintings and several immense chandeliers. As this version is a spin-off, there is no actual courting between Romeo the host and Juliet the masked intruder who has been brought up without knowing her true identity as a Capulet. Even more so, the youngsters now meet for the second time, the first time being when he saved Red Whirlwind's life from pursuing soldiers. At the ball, when Juliet realizes the young man who has saved her is her archenemy's son, she starts to run away, down some stairs in a Cinderella-like scene. As she descends, she finds it strange that she can recognize the places she sees, and Romeo follows her out of curiosity preventing her from falling after she has tripped. They share a romantic moment but Juliet then leaves, without however leaving any shoe behind. The overall impression is that the familiar plot has been turned into a fairy-tale with a "happily ever after" sort of ending.

\section{Juliet's Bedroom}

Juliet's bedroom is the representation of the most intimate space in the whole play/manga. It is also a gendered space, where the young girl occupying it has left her mark. As all three bedrooms are feminine, Romeo appears as a male intruder, threatening to occupy Juliet's most intimate territory-both her bedroom and her body.

The British manga frame depicting Juliet's room after the wedding night focuses on the bed, which is drawn in the foreground. In this twenty-first century setting, Juliet's bedroom is bright, furnished with the necessary items for a teenager. It is also divided into two main areas: one dedicated to study (there is a desk and some bookshelves on the wall), and the other to sleeping (with a simple, minimalist bed). In addition to these, there are some paintings, including a family portrait, posters on the walls, as well as a caged blackbird symbolic of Juliet's situation as trapped between her obedience to her family and her love for her husband. Nevertheless, it is the bed that catches the viewer's eye, as a central visual metaphor of Romeo and Juliet's relationship. The bed seems carefully made, with the bedcover neatly laid, so as to hide any trace of the previous night. Juliet is sitting on it, while Romeo lounges on the floor, his head in her lap, both of them facing the French doors to Juliet's balcony. The fact that the doors are closed seems to foreshadow their doomed love and future together.

The American version, faithful to the Elizabethan original, depicts a rather sparsely furnished room, light and airy but with an old-fashioned canopy bed in the centre. The curtains of the bed are tied to the bedposts, so viewers can see the unmade bed, where Juliet is still lying sensually under the blanket and talking to Romeo who is standing by the open window, looking outside. The 
open window may simultaneously convey hope for their momentary relationship but also the necessity of Romeo's flight to save his life.

By contrast again, in the Japanese version Juliet's bedroom centres on the vanity table, where Juliet's maid Cordelia brushes her hair. If in the other mangas viewers are introduced into Juliet's personal space after the wedding night, here viewers enter this space long before the youngsters' actual wedding night. The room looks stuffy and old, with walls and the floor made of bricks and with no visible window-most likely to protect Juliet's identity. There are only three furniture items: the bed (neatly made), the vanity table with a three way mirror, which is the most elaborate and impressive piece, and the chair in front of it. It is noteworthy that Romeo never actually enters this personal space of Juliet's and readers/viewers see Juliet seated at the vanity table, as if trying to put together various pieces of her identity: throughout the story, she appears first as the vigilante Red Whirlwind, living her life until sixteen years of age crossdressed as a boy named Odin, and being Juliet only in the privacy of the home where she is protected by Capulet loyalists. In this manga version, Juliet's bedroom retains its female gendered aspect, remaining untainted by male intrusion.

\section{Conclusions}

Translation-no matter if it is from one language to another or from one code to another-always involves losses and gains. Manga transmediations are no exceptions. While the British and Japanese versions re-contextualize the plot, moving it to the real modern city of Tokyo or the fabulous Neo Verona, the American version remains faithful to the original, preserving Renaissance Verona as the setting.

Moreover, manga is a cultural space where the three cultures enter in contact with one another. All three mangas discussed add meaning to the family feud and to especially to Juliet. Thus, the British version presents the feud as a Yakuza clan territorial conflict, the American version renders it as a rather trivial affair, linking it to the haggling market space, while the Japanese spin-off approaches it as a fairy-tale-like good versus evil conflict. If the British manga provides insight into the depth of the feud, the American one minimalizes it, focusing on the forbidden love story, whereas the Japanese manga is the most fantastic, relying heavily on intertextuality with many of Shakespeare's other plays.

In a similar way, the British Juliet is associated with ice, coldness and, by extension, maybe even frigidity, the American Juliet is turned into edible commodity through associations with food, whereas the Japanese Juliet has not one but two secret identities. 
All in all, each of the three manga adaptations conveys a different attitude to Shakespeare's work: the British manga focuses on the versatility, the cultural mobility of Shakespeare's plays, emphasizing once again the idea that he is "for all times"; the American manga comes across as a case of bardolatry, even in terms of the linguistic space, while the Japanese spin-off offers a "taste" of Shakespeare's imagined world(s). They all highlight the fact that such new Shakespearean spaces may well be real or deceptive, yet they also "open his plays to the possibility of ceaseless change." (Greenblatt 77)

\section{Works Cited}

Greenblatt, Stephen. "Cultural mobility: an introduction." Cultural Mobility: A Manifesto. Eds. Stephen Greenblatt, Ines Županov, Reinhard Meyer-Kalkus, Heike Paul, Pál Nyíri, and Friederike Pannewick. Cambridge: Cambridge University Press, 2010. 1-23. Print.

Greenblatt, Stephen. "Theatrical Mobility." Cultural Mobility: A Manifesto. Eds. Stephen Greenblatt, Ines Županov, Reinhard Meyer-Kalkus, Heike Paul, Pál Nyíri, and Friederike Pannewick. Cambridge: Cambridge University Press, 2010. 75-95. Print.

Habermann, Ina and Michelle Witen (eds.). Shakespeare and Space: Theatrical Explorations of the Spatial Paradigm. London: Palgrave Macmillan, 2016. Print.

Jensen, Michael P. "Shakespeare and the Comic Book." The Edinburgh Companion to Shakespeare and the Arts. Eds. Mark Thornton Burnett, Adrian Streete and Ramona Wray. Edinburgh: Edinburgh University Press, 2011. 388-407. Print.

Reynolds, Bryan and Janna Segal. "Fugitive Explorations in Romeo and Juliet: Transversal Travel through R\&Jspace." Journal for Early Modern Cultural Studies 5.2 (2005): 37-70. Print.

Şerban, Andreea. "Manga-fying Shakespeare. 'You must translate. 'Tis fit we understand [it].' (Hamlet IV.1.2)." The European English Messenger 23.1 (2014): 21-27. Print.

Şerban, Andreea. “'Arise, Fair Sun,' and Let Down Your Hair: Romeo and Juliet's Balcony Scene for Kids and Teens." What's in a Balcony Scene? A Study on Shakespeare's Romeo and Juliet and its Adaptations. Ed. Luminiţa Frenţiu. Newcastle upon Tyne: Cambridge Scholars Publishing, 2016. 65-76. Print.

Shakespeare, William. Romeo and Juliet, London, 2003 (1594), http://www.opensourceshakespeare.org/views/plays/play_view.php?WorkID=ro meojuliet\&Act=1\&Scene=2\&Scope=scene. Web. 3 March 2017.

Shakespeare, William and COM (artist). 2010. Romeo X Juliet. Translated by Kate Beckwitt; Gonzo and SPWT contributors. New York: Yen Press.

Shakespeare, William, Richard Appignanesi, Sonia Leong (artist). Romeo and Juliet. Manga Shakespeare. London: Self Made Hero, 2010 (2007). Print.

Shakespeare, William, Adam Sexton, Yali Lin (artist). Shakespeare's Romeo and Juliet. The Manga Edition. Hobocken, NJ: Wiley Publishing, 2008. Print. 


\section{ANDREEA ȘERBAN}

Wetmore, Jr., Kevin J. "Shakespeare and Teenagers." The Edinburgh Companion to Shakespeare and the Arts. Eds. Mark Thornton Burnett, Adrian Streete and Ramona Wray. Edinburgh: Edinburgh University Press, 2011. 377-387. Print. 